\title{
AMPK Activation by Oncogenesis Is Required to Maintain Cancer Cell Proliferation in Astrocytic Tumors
}

\author{
Marcos Ríos ${ }^{1}$, Marc Foretz ${ }^{4}$, Benoit Viollet ${ }^{4}$, Angel Prieto ${ }^{3}$, Máximo Fraga ${ }^{2}$, Jose A. Costoya ${ }^{1}$, and \\ Rosa Señarís $^{1}$
}

\begin{abstract}
5 -AMP-activated protein kinase (AMPK) is an energy sensor that controls cell metabolism, and it has been related to apoptosis and cell-cycle arrest. Although its role in metabolic homeostasis is well documented, its function in cancer is much less clear. In this study, we examined the role of AMPK in a mouse model of astrocytoma driven by oncogenic H-Ras ${ }^{\mathrm{V} 12}$ and/or with PTEN deletion based on the common constitutive activation of the Raf/MEK/ERK and PI3K/AKT cascades in human astrocytomas. We also evaluated the activity and role of AMPK in human glioblastoma cells and xenografts. AMPK was constitutively activated in astrocytes expressing oncogenic H-Ras ${ }^{\mathrm{V} 12}$ in parallel with high cell division rates. Genetic deletion of AMPK or attenuation of its activity in these cells was sufficient to reduce cell proliferation. The levels of pAMK were always related to the levels of phosphorylated retinoblastoma $(\mathrm{Rb})$ at Ser804, which may indicate an AMPKmediated phosphorylation of Rb. We confirmed this AMPK-Rb relationship in human glioblastoma cell lines and xenografts. In clinical specimens of human glioblastoma, elevated levels of activated AMPK appeared especially in areas of high proliferation surrounding the blood vessels. Together, our findings indicate that the initiation and progression of astrocytic tumors relies upon AMPK-dependent control of the cell cycle, thereby identifying AMPK as a candidate therapeutic target in this setting. Cancer Res; 73(8); 2628-38. (C2013 $A A C R$.
\end{abstract}

\section{Introduction}

In the 1920s, a relationship between cellular metabolism and tumorigenesis was first proposed by Warburg and colleagues, showing that cancer cells exhibited an increase in glycolysis even in conditions of high oxygen levels (1). Since then many modifications in intermediary metabolism have been described in cancer cells, but the molecular mechanisms that interconnect the signaling pathways controlling metabolism and cell growth have only begun to be elucidated. One of the

Authors' Affiliations: ${ }^{1}$ Departamento de Fisioloxía, CIMUS, Facultade de Medicina, ${ }^{2}$ Departamento de Anatomia Patolóxica e Ciencias Forenses, Universidade de Santiago de Compostela; ${ }^{3}$ Servicio de Neurociruxía, Complejo Hospitalario Universitario de Santiago de Compostela, Santiago de Compostela, Spain; and ${ }^{4}$ Institut National de la Santé et de la Recherche Medicale (INSERM), U1016, CNRS UMR8104, Institut Cochin, Université Paris 5, Paris, France

Note: Supplementary data for this article are available at Cancer Research Online (http://cancerres.aacrjournals.org/)

R. Señarís and J.A. Costoya contributed equally to this work.

Corresponding Authors: Rosa Señarís, Departamento de Fisioloxía, CIMUS, IDIS, Facultade de Medicina, Universidade de Santiago de Compostela, Santiago de Compostela 15782, Spain. Phone: 34-881815442; Fax: 34-881815403; E-mail: rosa.senaris@usc.es; and Jose A. Costoya, Molecular Oncology Laboratory MOL, Departamento de Fisioloxía, CIMUS, IDIS, Facultade de Medicina, Universidade de Santiago de Compostela, Santiago de Compostela 15782, Spain. Phone 34-881815449; Fax: 34881815403; E-mail: josea.costoya@usc.es

doi: 10.1158/0008-5472.CAN-12-0861

(C)2013 American Association for Cancer Research. plausible links between cell metabolism and cancer is the fuelsensing enzyme 5'-AMP-activated protein kinase (AMPK). This kinase has a major role in the regulation of glucose, lipid, and protein metabolism in response to stimuli such as changes in fuel availability, oxidative stress, heat shock, and hormones (2). AMPK is a heterotrimer that contains 1 catalytic ( $\alpha 1$ or $\alpha 2), 1$ regulatory $(\beta 1$ or $\beta 2)$, and $1 \mathrm{AMP} / \mathrm{ATP}$-binding $(\gamma 1, \gamma 2$, or $\gamma 3)$ subunit (2). Decreases in the cellular energy state, as reflected by an increase in the AMP/ATP ratio, induce conformational changes in AMPK that makes it susceptible to phosphorylation and activation by AMPK kinases (2). Once activated, AMPK restores energetic balance stimulating catabolic pathways that enhance ATP generation and inhibiting others that consume ATP but are not acutely necessary for survival (3). Recent findings have also pointed to a link between AMPK and cell growth. First, it was shown that the tumor suppressor LKB1 is a kinase that phosphorylates and activates AMPK and that another tumor suppressor, tuberous sclerosis complex 2 (TSC2), is activated by AMPK $(4,5)$. TSC2 activation by AMPK results in suppression of mTORC1 kinase activity. Second, AMPK was shown to modulate p53-dependent apoptosis by p53 phosphorylation (6). Third, several studies indicated that the products of two p53 target genes, sestrin 1 and 2, increased AMPK activity inducing mTOR signaling inhibition (7). Altogether, these data seemed to indicate a role of AMPK in cell growth arrest and cell death. Accordingly, activation of AMPK by energy depletion would function as a metabolic checkpoint, in which normal cells with intact AMPK signaling undergo cell-cycle arrest, driving proliferation only when cell 
energy is sufficient to guarantee a successful cell division. It was shown that some cancer cells exhibit a defective AMPK activation

(e.g., LKB1 deficiency) or alterations in key components of the AMPK pathway (e.g., TSC2 or p53 deficiency), which would uncouple fuel signals from growth signals, allowing tumor cells to divide under abnormal nutrient conditions. AMPK activation was then proposed as a therapeutic approach for cancer (2). However, very recent reports have shown high pAMPK levels in some tumors and a role of AMPK in tumor cell growth and survival $(8,9)$. Therefore, the function of AMPK in the biology of cancer is far from being understood.

The main objective of the present study was to give further insight into the regulatory role of AMPK in cell growth and proliferation in tumors. To accomplish this objective, we evaluated the function of AMPK in both mice and human astrocytic tumors. To dissect out the mechanisms underlying the effect of AMPK in astrocytoma cell growth, we first reproduced different molecular events that lead from tumor initiation to progression in the mouse. For this purpose, we used astrocytes expressing HRas ${ }^{\mathrm{V} 12}$ and/or with Pten deletion because a constitutive activation of Raf/MEK/ERK and PI3K/ AKT cascades are common alterations in human astrocytomas (10) and both signaling pathways regulate cell metabolism (1113). We then confirmed the role of AMPK in human glioblastoma cell lines as well as in human glioblastoma xenografts in severe combined immunodeficient mice (SCID) mice. Finally, we examined the level of AMPK activation and activity in human glioblastoma tissue samples.

Here, we showed that human glioblastomas exhibit high levels of AMPK activity, and we showed that AMPK activation is essential for the proliferation of astrocytic tumor cells by promoting cell-cycle progression in both mice and human.

\section{Materials and Methods}

\section{Cell culture, transfection, and retroviral infection}

Cortical astrocytes were obtained from cerebral cortices of 3-day-old Pten loxp/loxp $^{\text {or } A M P K \alpha^{\text {loxp/Loxp }} \text { mice and maintained }}$ in culture for 4 to 6 days. $A M P K \alpha^{\text {loxP } / \text { loxP }}$ mice were generated as previously described by crossing $A M P K \alpha I^{\text {loxp/loxP }}$ and $A M P K \alpha 2^{\text {loxP/loxP }}(14,15)$. The care and use of experimental animals was in accordance with institutional guidelines. Cells were cultured in Dulbecco's Modified Eagle's Medium (DMEM) supplemented with $10 \%$ FBS and to express HRas ${ }^{\mathrm{V} 12}$ and/or Cre-recombinase ecotropic retrovirus were used as previously published (16).

U87MG and U373MG human glioma cell lines were obtained from J. Seoane (Vall d'Hebron Instituto de Oncología, Barcelona, Spain) in 2011. Both cell lines were periodically authenticated by morphologic inspection and tested negative for Mycoplasma contamination by PCR tests. Cells were cultured in DMEM supplemented with $10 \%$ FBS. For RNA interference (RNAi) experiments, 3 different commercial AMPK $\alpha$ ( $\alpha 1$ and $\alpha 2)$ siRNAs (sc-45312A, sc-45312B, and sc-45312C), and control siRNA (sc-37007) were obtained from Santa Cruz Biotechnology. Transfection of cell lines with $10 \mathrm{and} /$ or $20 \mathrm{nmol} / \mathrm{L}$ of siRNAs was conducted with jetPRIME (Polyplus transfection) following the manufacturer's recommendations. Cells were lysed after 48 hours posttransfection and used for subsequent experiments.

For AMPK activation/inhibition, astrocytes and cell lines were cultured in the presence of $0.2 \mathrm{mmol} / \mathrm{L} 5$-Aminoimidazole-4-carboxyamide ribonucleoside (AICAR) or $10 \mu \mathrm{mol} / \mathrm{L}$ compound $\mathrm{C}$ for the indicated times.

All treatments were conducted in astrocytes cultured for 7 days after the infection in complete medium (DMEM supplemented with $10 \%$ FBS) except specifically indicated in the text.

\section{Tumor growth in SCID mice}

SCID mice were fed ad libitum and maintained on a 12-hour light-dark cycle at a controlled temperature. To estimate the effect of compound $\mathrm{C}$ in a xenograft tumor model, tumors were induced by subcutaneous injection of $2.5 \times 10^{6} \mathrm{U} 87 \mathrm{MG}$ cells, resuspended in $100 \mu \mathrm{L}$ of PBS into the right flank of 6- to 8week-old SCID mice (20-25 g). When subcutaneous tumors had reached a detectable size of $30 \mathrm{~mm}^{3}$, mice were randomized into 2 groups: one group was treated with compound C, administered as a single dose of $10 \mathrm{mg} / \mathrm{kg}$ [intraperitoneal (i.p.)]; the second group received 1 injection of the vehicle (100 $\mu \mathrm{L}$ PBS/DMSO 10\%). Mice were monitored daily for tumor size (using a calliper) and health status. Tumor volume was calculated by the formula: [(length ${ }^{2} \times$ width)/2] until the end of the experiment (17). When the tumor exceeded $2,000 \mathrm{~mm}^{3}$, animals were sacrificed and this date was used to plot the Kaplan-Meier survival curve.

\section{Growth curves and BrdUrd incorporation}

We determined cell number in an indirect way using crystal violet as it has been previously reported (18). To assess relative cell numbers, cells were grown in 24 multi-well plates and treated in each case as indicated in the text. At 0, 2, 4, and 7 days, cells were washed with PBS, fixed with methanol:acetic acid (3:1) for 20 minutes, stained with crystal violet for an additional 20 minutes, washed 5 times with PBS, and air dried. Dye was eluted from cells at room temperature by the addition of $1 \mathrm{~mL}$ of $10 \%$ acetic acid and absorbances were measured at $595 \mathrm{~nm}$.

DNA replication was determined by detecting bromodeoxyuridine (BrdUrd) incorporation. Cells grown over $1,7 \mathrm{~cm}^{2}$ coverslips were treated in each case as indicated in the text and then labeled 5 hours with $10 \mu \mathrm{mol} / \mathrm{L}$ BrdUrd for astrocytes and 1 hour for cell lines. Cells were fixed with $75 \%$ ethanol, denaturalised for 30 minutes in $4 \mathrm{~N} \mathrm{HCl}$, and blocked with $1 \%$ bovine serum albumin. Then, cells were incubated 1 hour at room temperature with anti-BrdUrd antibody and microscopic visualization was possible using a Cy3-tagged secondary antibody (Jackson ImmunoResearch). Mounting medium containing 4',6-diamidino-2-phenylindole (DAPI) was used and cells were visualized by inmunofluorescence.

\section{Patients and tissue sampling}

Human glioblastoma and normal human brain tissue samples were obtained from patients of the Neurosurgery Service of the University Hospital of Santiago de Compostela (Santiago 
de Compostela, Spain). The study was conducted after approval of the Ethics committee of the Xunta de Galicia. A small piece of the tumor and of human brain samples from epilepsy surgery sent to the Pathological Service was immediately frozen and used for Western blot analysis. The immunohistochemistry (IHC) was carried out in formalin-fixed paraffinembedded samples from human glioblastomas and human normal brain from the files of the Pathological Service and Biobank of the University Hospital of Santiago de Compostela.

\section{Data presentation and statistical analysis}

Data represent mean \pm SEM. Before all statistical analyses, data were examined for assumptions of normality of variance using the Kolmogorov-Smirnov test. The $t$ test, one-way, or two-way ANOVA were used to calculate statistical significance. Survival curves were estimated by the Kaplan-Meier method.

\section{Results}

\section{AMPK is activated by oncogenic events}

We used a cellular model of mice astrocytoma with astrocytes expressing HRas ${ }^{\mathrm{V} 12}$ and/or with an activated PI3K/AKT pathway by Pten loss. These signaling pathways are frequently activated in human astrocytomas (13). Although Ras mutations are not found in human astrocytic tumors, a hyperactiva- tion of fibroblast growth factor and EGF receptors is frequently observed, consequently increasing Ras signaling.

As expected, astrocytes with HRas ${ }^{\mathrm{V} 12}$ enhanced extracellular signal-regulated kinase (ERK)1/2 phosphorylation, and Pten deletion induced AKT phosphorylation (Supplementary Fig. S1A and S1B). Ras pathway activation was related with a high proliferation level, however, no significant changes in cell growth rate were observed in Pten-null cells (Fig. 1A). Furthermore, we were unable to detect significant levels of apoptosis and senescence in any of the experimental groups, as it has already been shown (16).

Interestingly an increased AMPK activation, determined by AMPK phosphorylation at the residue Thr172 (required for the mammalian AMPK activation), and a higher AMPK activity, assessed by ACC phosphorylation at the residue Ser79 (a wellestablished AMPK target) was found in astrocytes expressing $\mathrm{HRas}^{\mathrm{V} 12}$ and/or Pten deletion. A greater effect was shown in the cells with oncogenic Ras (Fig. 1B). Total levels of AMPK and ACC were unchanged (Supplementary Fig. S1C and S1D). This AMPK activation was likely dependent on the oncogenic events and not due to nutrient depletion caused by a high proliferation rate because phosphorylation levels of both AMPK and ACC were increased similarly in cells kept in culture medium for 7 days, or 24 hours after fresh complete medium was added to the cells (Fig. 1C). Furthermore, no differences were found in

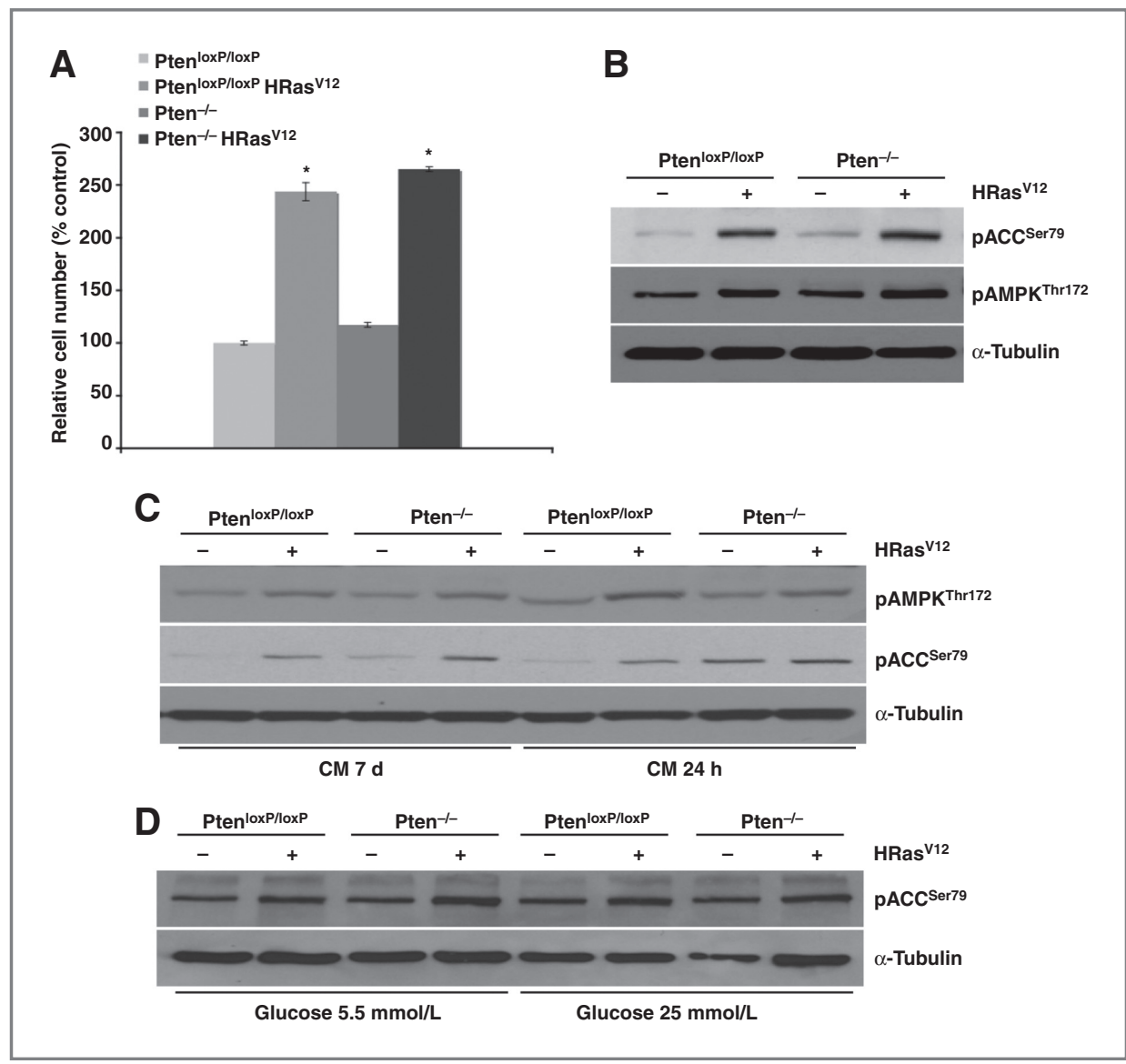

Figure 1. AMPK is activated by HRas ${ }^{\mathrm{v} 12}$ expression and Pten deletion in astrocytes. Neonatal mice astrocytes were infected with retroviral vectors encoding $\mathrm{HRas}^{\mathrm{V} 12}$ and/or Cre-recombinase, generating 4 different genotypes: Pten $^{\text {loxP/loxP }}$, Pten ${ }^{\text {loxP/loxP }}$ HRas $^{\text {V12, }}$, Pten $^{-/-}$, and Pten ${ }^{-1-}$ HRas $^{\text {V12 }}$ Cells were maintained in culture for 7 days. Data were represented as mean \pm SEM from at least 3 independent experiments. A, relative cell number determined the seventh day in culture by crystal violet ${ }^{*}, P<0.001$ vs. $P$ ten ${ }^{\text {loxP/loxP }}$ ). $B, A M P K$ activation was examined by immunoblot analysis of pAMPK $^{\text {Thr172 }}$, and pACC Ser79 $^{\text {. }}$ $\alpha$-Tubulin was used as a loading control. C, pAMPK ${ }^{\text {Thr172, }}$ $\mathrm{pACC}^{\text {Ser79, }}$, and $\alpha$-tubulin levels when cells were cultured during 7 days (CM 7d) or when new medium was added on the sixth day in culture 24 hours before protein extraction (CM 24h). D,

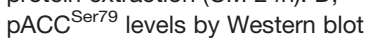
analysis in astrocytes cultured in the presence of 5.5 or $25 \mathrm{mmol} / \mathrm{L}$ D-glucose. 
the level of activation of AMPK in astrocytes with oncogenic Ras or Pten loss cultured with either 5 or $25 \mathrm{mmol} / \mathrm{L}$ glucose (Fig. 1D).

\section{AMPK is a mediator of cell proliferation}

Previous reports have shown that AMPK activation reduces cell proliferation by stimulation of $\mathrm{TSC} 2$, consequently inhibiting mTORC1 pathway and by phosphorylation of p53. However, we show here that astrocytes with oncogenic Ras, with or without AKT activation maintained high proliferation rates in the presence of an elevated AMPK activity. HRas $^{\text {V12 }}$-expressing astrocytes and cells without Pten exhibited levels of pmTOR ${ }^{\text {Ser2448 }}$ similar to those observed in control cells (Supplementary Fig. S2A). These results probably reflect that AMPK was counteracting the effect of Ras and AKT on TSC2, inhibiting the anabolic effects of both signaling pathways.

To determine possible roles of oncogenic AMPK activation, we first analyzed pAMPK cell localization. Immunofluorescence analysis showed that pAMPK was mainly localized in the cytoplasm of control cells, whereas oncogenic events induced an increase in pAMPK nuclear levels (Fig. 2A and $\mathrm{B}$ ). As it has previously been shown that AMPK nuclear localization was related to a higher expression of AMPK $\beta 1$ (19), we determined the levels of both АMPK $\beta 1$ and AMPK $\beta 2$. Interestingly, we found increased AMPK $\beta 1$ levels in HRas ${ }^{\mathrm{V} 12}$ and Pten $^{-/-}$cells and a reduced content of AMPK $\beta 2$ in HRas ${ }^{\mathrm{V} 12}$ astrocytes (Fig. $2 \mathrm{C}$ and Supplementary Fig. S2C). Furthermore, subcellular fractionation data confirmed a nuclear increase in pAMPK and $\mathrm{pRb}^{\mathrm{Ser} 800 / 804}$ levels, a recently described AMPK target (19), in these groups of cells (Fig. 2D). Nuclear to cytoplasmic ratio (Nuc:cyt) of pAMPK was significantly increased in oncogenic Ras-expressing cells (Supplementary Fig. S2D). On the other hand, total AMPK $\alpha$ levels were also increased in the nuclear fraction in the astrocytes with the oncogenic events (Supplementary Fig. S2B).

We next investigated whether AMPK activation or inhibition had any effect on the proliferative capacity of our cells. To accomplish this, we used AICAR (an adenosine analog, rapidly phosphorylated, which mimics the activating effects of AMP on AMPK) or compound C (a compound that acts as a potent, selective, reversible, and ATP-competitive inhibitor of AMPK). Accordingly, astrocytes after 6 days in culture were incubated with AICAR or with compound C for 24 hours and BrdUrd incorporation was evaluated. In agreement with previous reports, AICAR induced AMPK activation, determined as higher levels of pACC, but concentrations higher than 0.2 $\mathrm{mmol} / \mathrm{L}$ reduced normal astrocytes viability (Supplementary Fig. S2E and S2F). We treated then the cells with AICAR at a concentration of $0.2 \mathrm{mmol} / \mathrm{L}$. Expression of oncogenic Ras induced a significant increase in BrdUrd incorporation, but treatment with $0.2 \mathrm{mmol} / \mathrm{L}$ AICAR for 24 hours did not change the levels of BrdUrd incorporation exhibited by nontreated cells (Fig. 2E). Interestingly, cells treated with compound $\mathrm{C}$ at concentrations that allowed cell viability in control astrocytes and previously described to reduce AMPK activation (refs. 9, 20-22; $10 \mu \mathrm{mol} / \mathrm{L}$; Supplementary Fig. S2G) signifi- cantly reduced BrdUrd incorporation in the cells expressing HRav $^{\mathrm{V} 12}$ (Fig. 2F). Decreased levels of $\mathrm{pRb}^{800 / 804}$ accompanied this reduction, whereas no effect on the phosphorylation of retinoblastoma $(\mathrm{Rb})$ was shown after treatment with AICAR (Fig. 2G and Supplementary Fig. S2H). These results suggest a mechanism by which AMPK regulates proliferation in astrocytoma cells with a hyperactivated Ras pathway.

\section{AMPK is necessary to maintain cell proliferation in mice astrocytes expressing oncogenic Ras and in human glioblastoma cell lines}

To further show the relationship between AMPK, Rb, and proliferation, we used primary cultures of AMPK $\alpha$-deficient mice astrocytes. We studied the effect of $A M P K$ deletion only in normal and in astrocytes expressing HRas ${ }^{\mathrm{V} 12}$ because Pten loss showed a very moderate effect on the parameters evaluated.

Astrocytes from mice with both AMPK catalytic subunits floxed were infected with H-Ras ${ }^{\mathrm{V} 12}$ and/or Cre-recombinase. As expected, $A M P K \alpha$ deletion reduced AMPK $\alpha$ levels and AMPK activity, as shown by ACC phosphorylation; the infected astrocytes with HRas ${ }^{\mathrm{V} 12}$ enhanced HRas levels (Supplementary Fig. S3A).

Cell growth rate and foci formation in astrocytes expressing HRas $^{\text {VI2 }}$ were reduced by $A M P K$ deletion, whereas no effect was shown in control cells. (Fig. 3A and B). Furthermore, growth inhibition in cells with oncogenic Ras expression and $A M P K$ deletion was not further increased when compound C (10 $\mu \mathrm{mol} / \mathrm{L}$ ) was added to the culture medium for 7 days (Supplementary Fig. S3B).

Proliferation, senescence, and apoptosis were determined in these cells. BrdUrd incorporation was determined in cells after 7 days in culture. Astrocytes with HRas ${ }^{\mathrm{V} 12}$ and $A M P K$ deletion showed a remarkable reduction in proliferation, with levels of BrdUrd incorporation within the range of control cells. Curiously, $A M P K$-null cells continued to proliferate as control astrocytes (Fig. 3C). On the other hand, only a very low senescence increase was observed in cells with $A M P K$ deletion and HRas ${ }^{\mathrm{V} 12}$ expression (Supplementary Fig. S3C), whereas no change in the levels of apoptosis was detected among the different groups (data not shown).

Finally, we determined $\mathrm{pRb}^{\mathrm{Ser} 800 / 804}$ levels in the 4 experimental groups. In agreement with our results with compound $\mathrm{C}$, we found a reduction in $\mathrm{pRb}^{\mathrm{Ser800/804}}$ in $A M P K$-deficient cells, in parallel to a decrease in ACC phosphorylation (Fig. 3D). This might explain the reduced rate of proliferation observed in $A M P K$-deleted astrocytes and confirm the important role of AMPK in maintaining the proliferation induced by HRas ${ }^{\mathrm{V} 12}$.

Because of the importance of AMPK in the proliferation of mice astrocytes expressing HRas ${ }^{\mathrm{V} 12}$ and/or Pten deletion, a plausible role of this kinase in human glioblastoma cells growth and proliferation was also investigated. We used U87MG and U373MG cell lines, as previous reports had shown that these astrocytoma/glioblastoma cell lines did not have mutations in the $R b$ gene $(23,24)$ We first inhibited AMPK activity with compound $\mathrm{C}(10 \mu \mathrm{mol} / \mathrm{L} ; 7$ days). Interestingly, this treatment blocked cell growth even in the U87MG cell line, which exhibits a more aggressive phenotype than the U373MG 


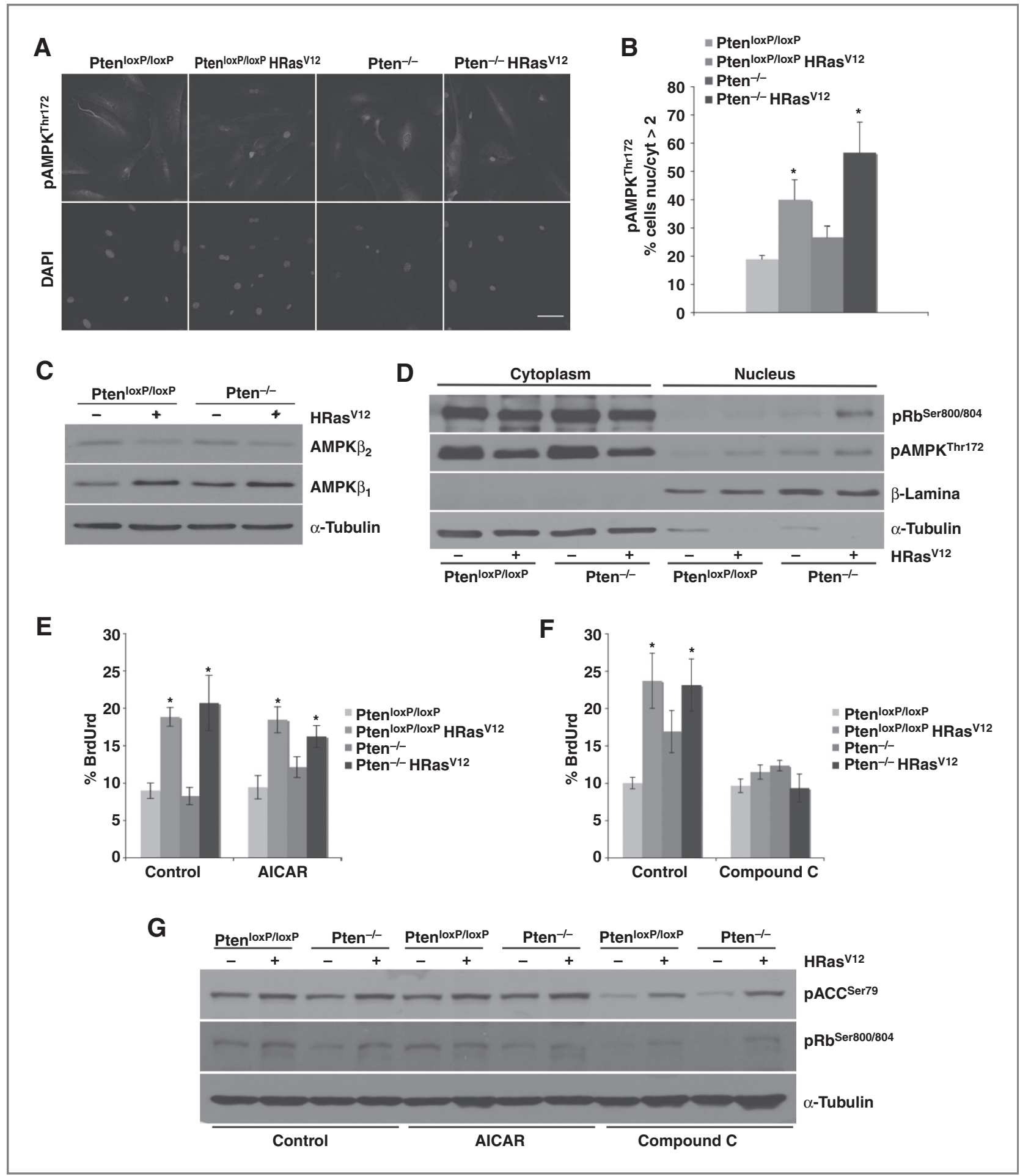

Figure 2. HRAS ${ }^{\mathrm{V} 12}$ expression induces nuclear pAMPK localization and subsequently Rb phosphorylation. Astrocytes of the 4 different genotypes Pten $^{\text {loxP/loxP }}$, Pten $^{\text {IoxP/loxP }}$ HRas $^{V 12}$, Pten $^{-/-}$, and Pten ${ }^{-/-}$HRas $^{V 12}$ were maintained in culture for 7 days. Data are represented as mean \pm SEM from at least 3 independent experiments. A, representative confocal microphotographs of pAMPK Thr172 immunofluorescence showing its nuclear and cytoplasmatic localization. Scale bar, $100 \mu \mathrm{m}$. B, nuclear and cytoplasmic fluorescence was quantified for each cell and the percentage of cells with a ratio of nucleus/cytoplasm pAMPK ${ }^{\text {Thr172 }}$ fluorescence $>2.5$ was represented $\left({ }^{*}, P<0.05\right.$ vs. $P$ ten ${ }^{\text {loxP }} /$ /loxP $)$. C, AMPK $\beta 1$, AMPK $\beta 2$, and $\alpha$-tubulin levels were determined by immunoblotting. D, cytoplasmic and nuclear extracts were used to determine pAMPK ${ }^{\text {Thr172 }}$ and $\mathrm{pRb}^{\mathrm{Ser800/804}}$. Levels of $\alpha$-tubulin and $\beta$-lamina were used as control. E and F, cells were treated with $0.2 \mathrm{mmol} / \mathrm{L}$ AICAR or $10 \mu \mathrm{mol} / \mathrm{L}$ compound $\mathrm{C}$ for 24 hours on the seventh day in culture. E, percentage

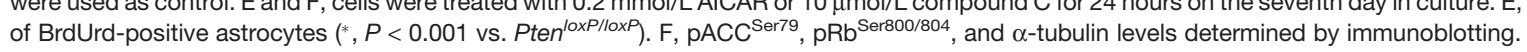




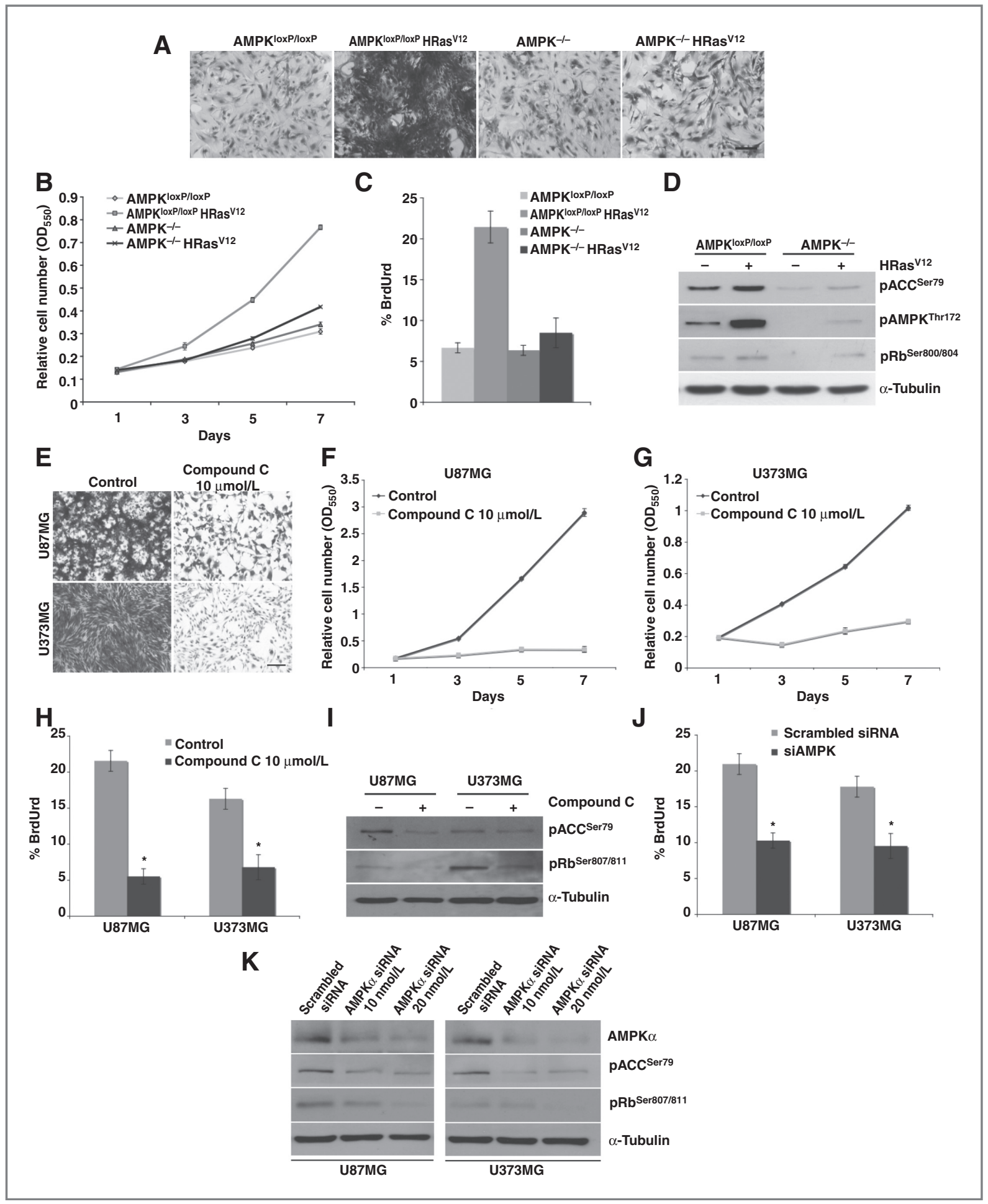

Figure 3. AMPK deletion, inhibition, or knocked down reduces growth in astrocytes-expressing HRAS ${ }^{\mathrm{V} 12}$ and human glioblastoma cell lines. Astrocytes of

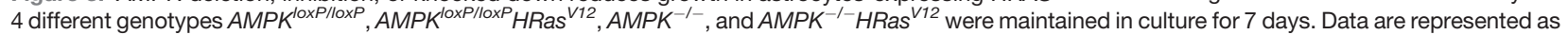
mean \pm SEM from at least 3 independent experiments. A, representative microphotographs of cells stained with crystal violet. Scale bar, $100 \mu \mathrm{m}$. $B$, growth curve showing relative cell number of the 4 experimental groups. C, percentage of BrdUrd-positive astrocytes $\left(^{*}, P<0.001\right.$ vs. AMPK ${ }^{\text {loxPlloxP }}$ ). $\mathrm{D}$, levels of $\mathrm{pAMPK}^{\mathrm{Thr} 172}$, $\mathrm{pACC}^{\text {Ser79, }} \mathrm{pRb}^{\text {Ser800/804 }}$, and $\alpha$-tubulin levels by Western blot analysis. E, F and G, U87MG and U373MG cells were treated with or without $10 \mu \mathrm{mol} / \mathrm{L}$ compound $\mathrm{C}$ for 7 days. E, representative microphotographs of crystal violet staining. $F$ and $G$, growth curve showing relative cell number. $\mathrm{H}$ and I, U87MG and U373MG cells were treated with $10 \mu \mathrm{mol} / \mathrm{L}$ compound $\mathrm{C}$ for 24 hours. H, percentage of BrdUrd-positive cells. I, pACC ${ }^{\text {Ser79 }}, \mathrm{pRb}^{\text {Ser800/804 }}$, and $\alpha$-tubulin levels by immunoblotting. J and K, U87MG and U373MG cells were transfected with 10 to $20 \mathrm{nmol} / \mathrm{L}$ of scrambled or AMPK $\alpha$ siRNA (48 hours). $\mathrm{J}$, percentage of BrdUrd-positive cells. K, pAMPK ${ }^{\text {Thr172 }}, \mathrm{pACC}^{\text {Ser79 }}, \mathrm{pRb}^{\text {Ser807/811 }}$, and $\alpha$-tubulin were determined by Western blot analysis $\left(^{*}, P<0.05\right.$ vs. control conditions). 
(Fig. 3E-G). Consistent with our previous results in mice astrocytes, compound $\mathrm{C}$ significantly reduced BrdUrd incorporation in both glioblastoma cell lines (Fig. $3 \mathrm{H}$ ) with no effect on senescence or apoptosis (data not shown). Moreover, we found lower levels of Rb phosphorylation in Ser ${ }^{807 / 811}$ (corresponding to $\mathrm{Ser}^{800 / 804}$ in mouse), in parallel to a pACC-reduced content in the cells treated with compound C (Fig. 3I). This effect of compound $C$ suggested a similar role of AMPK on cellcycle regulation in mice astrocytes expressing HRas ${ }^{\mathrm{V} 12}$ and/or Pten loss and in human glioblastoma cell lines.

To firmly establish a direct relationship between AMPK inhibition, Rb phosphorylation, and cell growth in these cells lines, we knocked down AMPK with siRNAs targeting the catalytic subunits of AMPK ( $\alpha 1$ and $\alpha 2)$. We studied the efficacy of 3 different siRNAs in reducing AMPK $\alpha$ levels and activity, by transfecting U87MG glioblastoma cells with the siRNAs (20 nmol/L; 48 hours), separately or in combinations. All siRNAs tested reduced AMPK levels and activity, as determined by pACC levels, although with different degrees of efficiency. The combination of the 3 pooled siRNAs reduced AMPK $\alpha$ and pACC levels further (Supplementary Fig. S3D and S3E). Likewise, individual and pooled siRNAs reduced $\mathrm{pRb}^{807 / 811}$ levels and BrdUrd incorporation. The decrease was greater with the 3 siRNAs together (Supplementary Fig. S3DS3F). Finally, we transfected U87MG and U373MG cells with the 3 pooled AMPK siRNAs ( 10 and $20 \mathrm{nmol} / \mathrm{L} ; 48$ hours), and we showed a significant reduction in BrdUrd incorporation and $\mathrm{pRb}^{807 / 811}$ levels in both cell lines (Fig. 3J and $\mathrm{K}$ ).

All these data showed the relevance of AMPK in human glioblastoma cell proliferation.

\section{AMPK inhibition decreases the in vivo growth of xenografts of human glioblastoma cell lines}

We have shown that AMPK inhibition reduced cell growth in human and murine astrocytic tumor models in vitro. However, stress conditions characteristic of a solid tumor microenvironment (hypoxia and metabolic stress) might affect the role of AMPK. To determine the effect of compound $\mathrm{C}$ on the growth of human glioblastoma cells in vivo, we injected U87MG tumor cells, subcutaneously, in immunodeficient SCID mice. We chose these cells because they are very tumorigenic in vivo in contrast to U373MG cells, which has been shown not to develop tumors in animals (25). Consistent with our in vitro findings, one single dose of compound C (10 mg/kg, i.p.) was able to reduce significantly the growth rate of U87MG tumors (Fig. 4A) and this treatment increased the survival of tumorbearing mice (Fig. 4B). We were unable to detect a higher effect when we treated the mice with several doses of compound $\mathrm{C}$ (Supplementary Fig. S4), which suggests that AMPK inhibition with compound $\mathrm{C}$ might produce a selection against growth of tumor cells with this pathway activation. In any case, our data reflect the important role of AMPK during in vivo glioblastoma tumor progression.

To further analyze the molecular mechanisms underlying this effect of AMPK, we determined apoptosis as well as cell proliferation levels in the tumor samples. IHC of cleaved caspase-3 did not show significant changes between tumors in animals with or without treatment (Fig. 4C). However, tumors in mice treated with compound $\mathrm{C}$ showed a reduction in BrdUrd incorporation and in the levels of p-histone H3 (Fig. $4 \mathrm{C}$ and $\mathrm{D}$ ), showing once again the relevant effect of AMPK in the control of cell proliferation. Finally, we studied the plausible AMPK-pRb signaling pathway in the tumors of animals with and without compound $\mathrm{C}$ treatment. Interestingly, $\mathrm{Rb}$ phosphorylation was decreased in parallel with a reduced AMPK activity (estimated by pACC Ser79 levels) in U87MG tumors treated with the AMPK antagonist (Fig. 4E). These results further illustrate that AMPK inhibiton reduce in vivo tumorigenesis.

\section{AMPK is activated in human glioblastomas}

To determine whether AMPK is activated in human glioblastomas, we carried out IHC to detect pACC ${ }^{\text {Ser79 }}$ on tissue samples from glioblastomas of 10 patients (Table 1 and Fig. $5 \mathrm{~A})$. Negative controls consisting of omission of primary antibody or substitution of primary antibody by normal rabbit serum (NRS) were conducted (Supplementary Fig. S5). High levels of pACC ${ }^{\text {Ser79 }}$ were observed in $100 \%$ of the tumors evaluated (Table 1). Normal brain tissue was either completely negative or showed only a weak staining for pACC ${ }^{\text {Ser79 }}$ (see representative photographs in Fig. 5A). In contrast, all glioblastoma tissue samples showed a heterogeneous pattern of positive cells. The immunoreactivity was found predominantly, if not entirely, in the cytoplasm. The highest number of

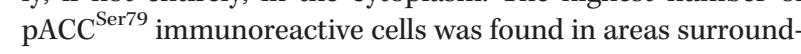
ing the blood vessels. We also determined Ki67 immunoreactivity as a proliferation index, and we found a good correlation between Ki67 and pACC ${ }^{\text {Ser79 }}$ immunoreactive levels, especially around the blood vessels (Table 1 and Fig. 5A). Very interestingly, high levels of pERK $^{\text {Thr202/Tyr204 }}$ were found in all the tumors evaluated in this study, especially in perivascular regions and areas with high proliferative rate (Table 1 and Fig. 5A). This localization of pACC cells shows that, in human glioblastomas, oncogenic events but not hypoxia, energy depletion, or low nutrients availability are responsible for AMPK activation. Finally, to further establish a relationship between AMPK activation and proliferation in human glioblastomas, we determined pAMPK, pACC, and $\mathrm{pRb}^{807 / 811}$ by Western blot analysis in 4 tissue samples of human glioblastomas and human normal brain. We found higher levels of pAMPK $^{\text {Thr172 }}$ and $\mathrm{pACC}^{\mathrm{Ser} 79}$ in the 4 tumors in relation with normal tissues, in agreement with the results of IHC (Fig. 5B). Furthermore and consistent with our previous results in mice astrocytes and in human glioblastoma cell lines, AMPK activation in the human glioblastoma tissue samples studied here was accompanied by high levels of $\mathrm{pRb}^{807 / 811}$.

In conclusion, our results show that AMPK has an important role in tumor growth, suggesting that an AMPK antagonist might potentially be used as a treatment in astrocytic tumors.

\section{Discussion}

While in various cancer cells a loss of appropriate AMPK signaling has been shown and AMPK activation has been proposed as a therapeutic approach to reduce cancer cell growth (2) in some others an activation of AMPK has been 


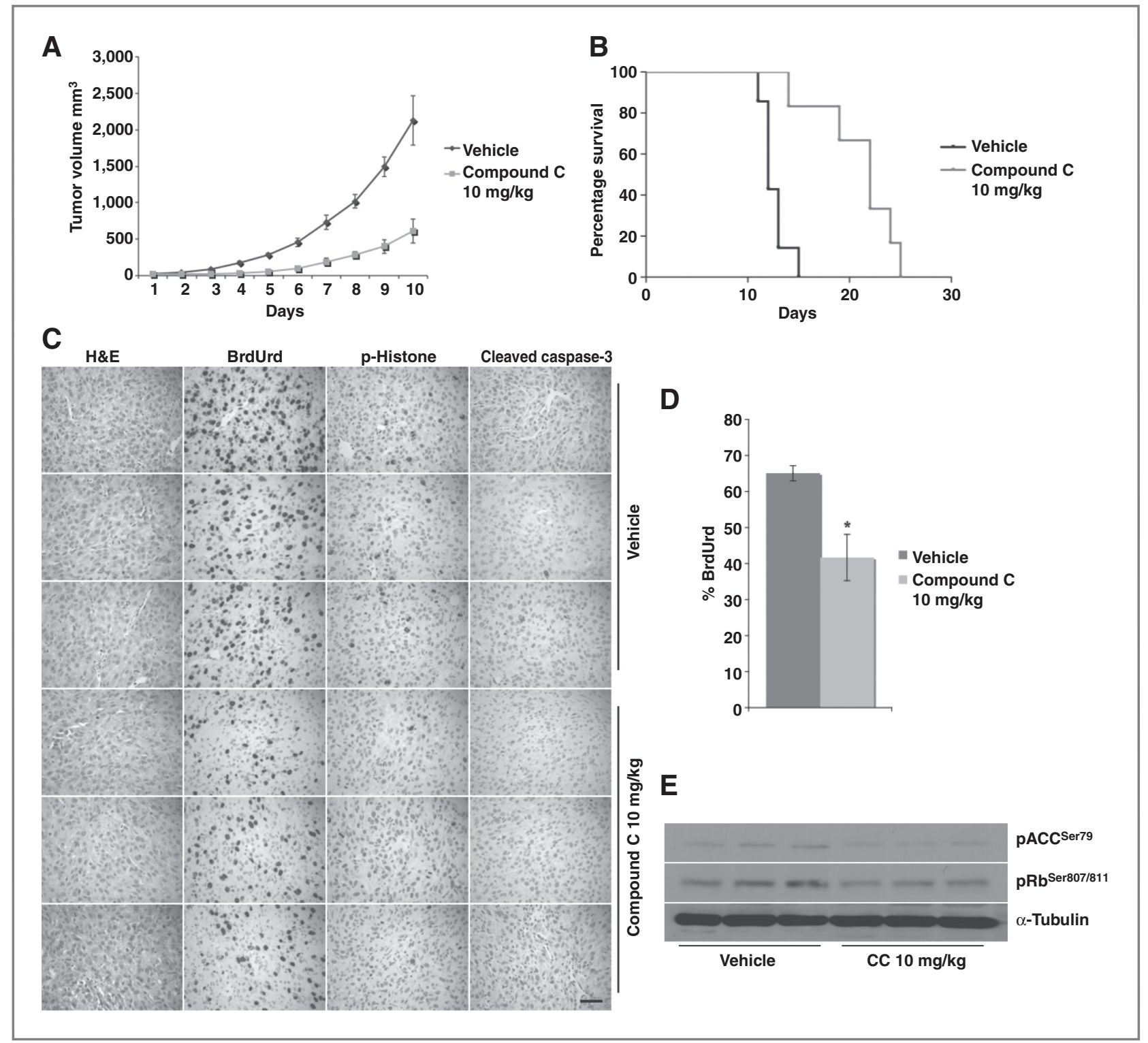

Figure 4. AMPK inhibition reduces tumor growth ratio in a xenograft model. U87MG cells were injected subcutaneously in SCID mice and when the tumors achieved $30 \mathrm{~mm}^{3}$ in size, mice were treated intraperitoneally with $10 \mathrm{mg} / \mathrm{kg}$ compound $\mathrm{C}$ or vehicle. A, tumor volume in mice treated with vehicle $(n=6)$ or compound C $(n=7)$. B, Kaplan-Meier curves of mice treated with vehicle $(n=6)$ or compound C $\left(n=7 ;{ }^{*}, P<0.0012\right.$ vs. animals treated with vehicle). $\mathrm{C}$, representative microphotographs of inmunohistochemistry showing BrdUrd incorporation, $\mathrm{pHistone} \mathrm{H}^{\mathrm{Ser} 10}$, and cleaved caspase-3 in tumors 8 days after vehicle or compound $C$ treatment. Scale bar, $100 \mu \mathrm{m}$. D, percentage of BrdUrd-positive cells in U87MG tumors 8 days after vehicle or compound $C$ treatment $\left({ }^{*}, P<0.0001\right.$ vs. nontreated tumors). E, ACC ${ }^{\text {Ser79 }}, \mathrm{pRb}^{\text {Ser807/811 }}$, and $\alpha$-tubulin levels were determined by Western blot analysis in U87MG tumors 8 days after vehicle or compound $\mathrm{C}$ treatment.

found, and a role of AMPK as a prosurvival factor in tumor cells has been described $(9,26)$.

In the present study, we evaluated the function and mechanism of action of AMPK in cell growth and proliferation in murine and human astrocytic tumors.

The novel and striking result of this study was the finding of AMPK as inductor of proliferation in these tumor cells. Specifically, we show here that oncogenic Ras and Pten deletion activates AMPK and that this activation stimulates cell proliferation. Furthermore, human glioblastoma exhibits elevated levels of activated AMPK and inhibition of AMPK in astrocytes expressing HRas ${ }^{\mathrm{V} 12}$ or in human glioblastoma cells significantly reduces cell growth.

A recent report has shown high pAMPK levels in rat gliomas (8), and it was shown that AMPK inhibition in prostate cancer cells or in mouse embryonic fibroblasts transformed by oncogenic Ras and SV40 large T-antigen reduced tumor growth $(9,27)$. Nevertheless, in these reports it was hypothesized that AMPK activation was a consequence of hypoxic or ischemic microenvironments. Here, we found that AMPK was highly activated in astrocytes expressing oncogenic Ras and Pten deletion not only after 7 days in culture, but also 24 hours 


\begin{tabular}{|c|c|c|c|c|c|c|c|}
\hline & $N$ & Method & $N^{a}$ & pACC & pACC perivascular & $\mathrm{pRb}$ & pERK \\
\hline \multirow{2}{*}{ Glioblastoma } & 14 & $\mathrm{IHC}$ & 10 & + & + & $\mathrm{n} / \mathrm{a}$ & + \\
\hline & & WB & 4 & + & $\mathrm{n} / \mathrm{a}$ & + & $\mathrm{n} / \mathrm{a}$ \\
\hline \multirow[t]{2}{*}{ Normal tissue } & 8 & $\mathrm{IHC}$ & 4 & - & - & $\mathrm{n} / \mathrm{a}$ & - \\
\hline & & WB & 4 & - & $\mathrm{n} / \mathrm{a}$ & - & $\mathrm{n} / \mathrm{a}$ \\
\hline
\end{tabular}

NOTE: Human glioblastoma tissue samples and human normal brain tissue analyzed by IHC or Western blot (WB) analysis. High levels $(+)$ and low levels $(-)$ of immunoreactivity.

Abbreviation: $\mathrm{n} / \mathrm{a}$, not available.

${ }^{a} \mathrm{~N}$, number of tissue samples from different patients evaluated.

after fresh culture medium was added to the cells, or in the presence of high concentrations of glucose $(25 \mathrm{mmol} / \mathrm{L})$, indicating that oncogenic signaling pathways, but not hypoxia or glucose depletion, were responsible for this activation. Moreover, the localization of cells with high levels of AMPK activity (determined as levels of pACC) in human glioblastomas, surrounding blood vessels, in areas with a high Ki67 proliferative index and high levels of pERK gives further support to this idea. In fact, it has been reported that AMPK activity may also be elevated under nonstressed conditions, for example by hormones such as leptin, adiponectin, and interleukin-6 (28). Curiously enough these adipokines have been implicated in the development and progression of some human cancers (29).

The activation of AMPK observed in astrocytes with oncogenic events and in the human glioblastomas probably indicates that AMPK provides metabolic support by directing cells to generate ATP to maintain energy homeostasis in these demanding conditions of high rate division. However, as our results suggest, the role of AMPK in cancer cells is not restricted to regulation of ATP levels, but is also involved in cell proliferation.

AMPK can be found both in the nucleus and the cytoplasm (30), and in mammalian cells, leptin (31) heat shock, and different types of stress $(32,33)$ have been reported to regulate the AMPK nuclear translocation. In this work, we show that nuclear localization of pAMPK was increased by HRas ${ }^{\mathrm{v} 12}$ expression or Pten loss. Previous data have related AMPK $\beta 1$ to nuclear localization of AMPK (19). In our hands, astrocytes with the oncogenic events exhibited higher levels of the AMPK $\beta 1$ subunits and a reduced content of the AMPK $\beta 2$, which reinforces the hypothesis of an important function of AMPK at the nuclear level in these cells. The increase of the nuclear localization of pAMPK would enhance the phosphorylation of its nuclear targets. Interestingly, it was recently shown that AMPK is an important kinase of Rb, specifically at

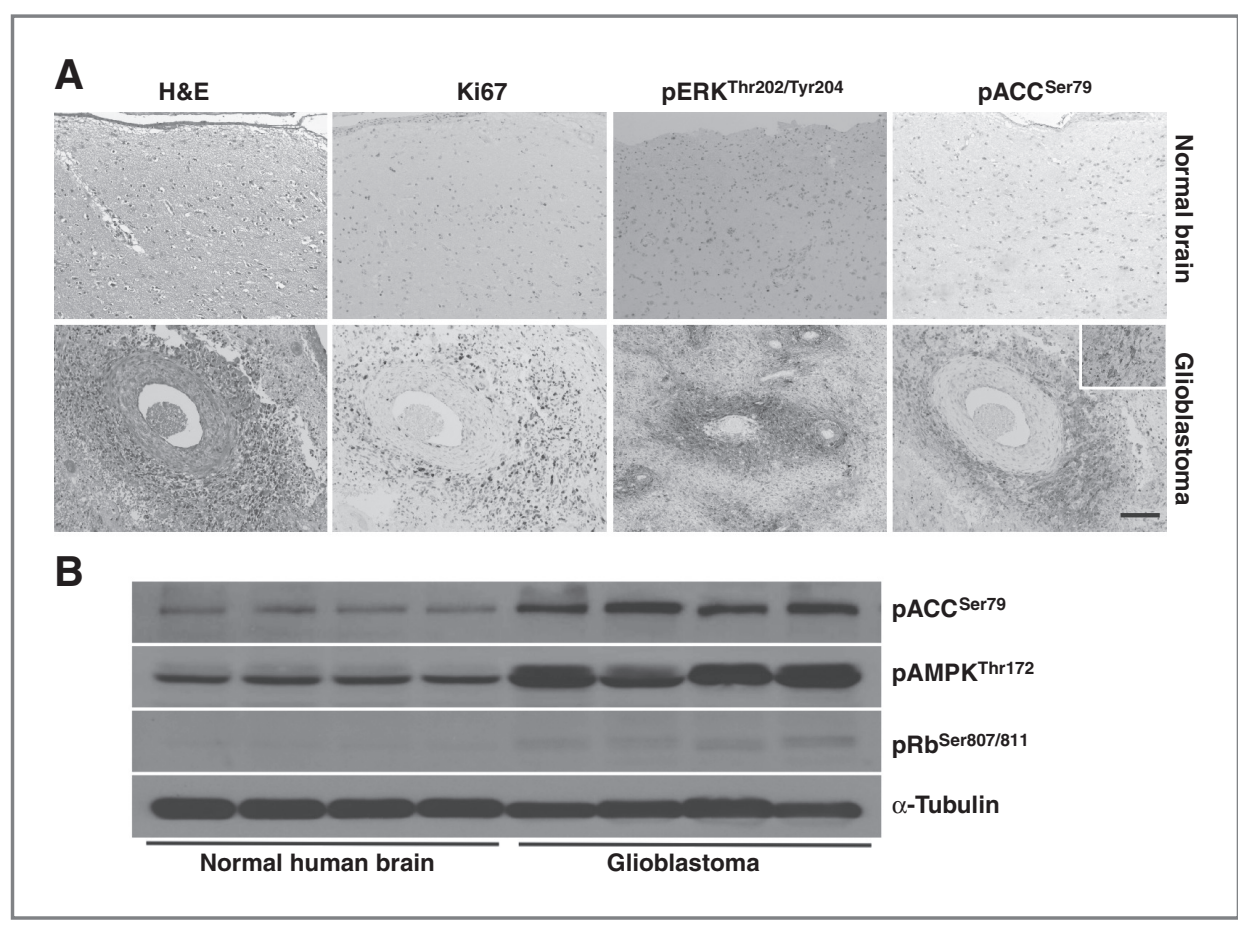

Figure 5. AMPK activity is increased in human glioblastomas especially in areas of high proliferation. A, representative microphotographs of normal human brain and human glioblastoma tissue samples stained with hematoxylin and eosin or processed by $\mathrm{IHC}$ to detect pACC ${ }^{\text {Ser79 }}$, Ki67, and pERK ${ }^{\text {Thr2O2/Tyr204 }}$. Scale bar, $100 \mu \mathrm{m}$. B, lysates of normal brain and glioblastoma tissue samples were used to determine pAMPK $^{\text {Thr172 }}$, pACC ${ }^{\text {Ser79, }}$, pRb Ser807/811, and $\alpha$-tubulin levels by immunoblotting 
$\mathrm{Ser}^{800 / 804}$, and that this phosphorylation has a key role during brain development by cell-cycle regulation (19). Our data showed that the increase of nuclear pAMPK by HRas ${ }^{\mathrm{V} 12}$ expression and/or Pten deletion was accompanied by higher levels of $\mathrm{pRb}^{\mathrm{Ser} 800 / 804}$, and this correlation was also found in the human glioblastoma cells lines. Furthermore, AMPK inhibition in mice astrocytes with compound $\mathrm{C}$ or AMPK deletion reduced significantly HRas ${ }^{\mathrm{V} 12}$-induced cell growth by decreasing BrdUrd incorporation and $\mathrm{pRb}^{\mathrm{Ser} 800 / 804}$ levels. This fundamental role of AMPK in regulating cell growth was also shown in U87MG and U373MG cell lines by blocking the expression of AMPK with siRNA or inhibiting AMPK activity by using compound $\mathrm{C}$.

Finally, we could demonstrate that a single intraperitoneal dose of compound $\mathrm{C}$ significantly decreased tumor growth of U87MG xenografts, increasing the survival of the tumor-bearing mice. Once more when we studied the molecular mechanisms underlying this inhibitory effect, we found reduced levels of $\mathrm{pRb} \mathrm{b}^{\mathrm{Ser807/811}}$ and proliferation.

The evidence presented here that AMPK activation and activity is induced early and remains elevated in human glioblastoma contributes to our understanding of the role of AMPK in astroglial tumor development, a type of brain tumors with a very poor survival rate. A better knowledge of tumor biology is essential for more specific targeting and the development of pharmacologic methods of treatment.

In conclusion, although it has been shown that AMPK acts as a survival factor protecting cells from hypoxia and nutrient deprivation, limiting ATP use in these situations (27, 34-37), AMPK is not required for growth in normal cells with abundance of nutrients. In contrast, in oncogenic situations (e.g., in the presence of oncogenic Ras signaling), AMPK activation is essential for cell growth and proliferation by regulating $\mathrm{Rb}$ phosphorylation, and therefore cell-cycle progression. By put-

\section{References}

1. Warburg $\mathrm{O}$, Wind F, Negelein $E$. The metabolism of tumors in the body. $J$ Gen Physiol 1927;8:519-30.

2. Fogarty S, Hardie DG. Development of protein kinase activators: AMPK as a target in metabolic disorders and cancer. Biochim Biophys Acta 2010;1804:581-91.

3. Towler MC, Hardie DG. AMP-activated protein kinase in metabolic control and insulin signaling. Circ Res 2007;100:328-41.

4. Inoki K, Ouyang H, Zhu T, Lindvall $\mathrm{C}$, Wang $\mathrm{Y}$, Zhang $\mathrm{X}$, et al. TSC2 integrates Wnt and energy signals via a coordinated phosphorylation by AMPK and GSK3 to regulate cell growth. Cell 2006;126: $955-68$.

5. Shaw RJ, Bardeesy N, Manning BD, Lopez L, Kosmatka M, DePinho RA, et al. The LKB1 tumor suppressor negatively regulates mTOR signaling. Cancer Cell 2004;6:91-9.

6. Jones RG, Plas DR, Kubek S, Buzzai M, Mu J, Xu Y, et al. AMPactivated protein kinase induces a p53-dependent metabolic checkpoint. Mol Cell 2005;18:283-93.

7. Budanov AV, Karin M. p53 target genes sestrin1 and sestrin2 connect genotoxic stress and mTOR signaling. Cell 2008;134: $451-60$.

8. Jang $T$, Calaoagan JM, Kwon E, Samuelsson S, Recht L, Laderoute KR. $5^{\prime}$-AMP-activated protein kinase activity is elevated early during primary brain tumor development in the rat. Int J Cancer 2011;128: 2230-9. ting all these data together, we propose that the use of AMPK inhibitors might be a good therapeutic approach in tumor cells with high levels of pAMPK.

\section{Disclosure of Potential Conflicts of Interest \\ No potential conflicts of interest were disclosed.}

\section{Disclaimer}

The funders had no role in study design, data collection and analysis, decision to publish, or preparation of the article.

\section{Authors' Contributions}

Conception and design: J.A. Costoya, R. Señarís

Development of methodology: M. Rios, J.A. Costoya, R. Señarís

Acquisition of data (provided animals, acquired and managed patients, provided facilities, etc.): M. Rios, M. Foretz, B. Viollet, A. Prieto, M. Fraga, J.A Costoya, R. Señarís

Analysis and interpretation of data (e.g., statistical analysis, biostatistics, computational analysis): M. Rios, M. Fraga, J.A. Costoya, R. Señarís

Writing, review, and/or revision of the manuscript: M. Rios, M. Foretz, A. Prieto, M. Fraga, J.A. Costoya, R. Señarís

Administrative, technical, or material support (i.e., reporting or organizing data, constructing databases): $\mathrm{M}$. Rios, B. Viollet, J.A. Costoya, R. Señarís

Study supervision: J.A. Costoya, R. Señarís

\section{Acknowledgments}

The authors thank Tomás García-Caballero (University of Santiago de Compostela) for his helpful discussion.

\section{Grant Support}

This work was supported by grants INCITE08PXIB208083PR (to R. Señarís) and PXIB208091PR (to J.A. Costoya) from Xunta de Galicia; SAF2008-00543 and SAF2009-08629 (to J.A. Costoya) from Ministerio de Ciencia e Innovación, Programa Nacional de Formación de Profesorado Universitario, and Ministerio de Ciencia e Innovación AP2006-03888 (to M. Rios).

The costs of publication of this article were defrayed in part by the payment of page charges. This article must therefore be hereby marked advertisement in accordance with 18 U.S.C. Section 1734 solely to indicate this fact.

Received March 8, 2012; revised January 21, 2013; accepted January 21, 2013; published OnlineFirst January 31, 2013.
9. Park HU, Suy S, Danner M, Dailey V, Zhang Y, Li H, et al. AMP-activated protein kinase promotes human prostate cancer cell growth and survival. Mol Cancer Ther 2009;8:733-41.

10. Ohgaki H, Kleihues P. Genetic pathways to primary and secondary glioblastoma. Am J Pathol 2007;170:1445-53.

11. Jones RG, Thompson CB. Tumor suppressors and cell metabolism: a recipe for cancer growth. Genes Dev 2009;23:537-48.

12. Plas $D R$, Thompson CB. Akt-dependent transformation: there is more to growth than just surviving. Oncogene 2005;24:7435-42.

13. Shaw RJ, Cantley LC. Ras, $\mathrm{PI}(3) \mathrm{K}$ and mTOR signalling controls tumour cell growth. Nature 2006;441:424-30.

14. Viollet B, Andreelli F, Jørgensen SB, Perrin C, Geloen A, Flamez D, et al. The AMP-activated protein kinase alpha2 catalytic subunit controls whole-body insulin sensitivity. J Clin Invest 2003;111:91-8.

15. Miller RA, Chu Q, Le Lay J, Scherer PE, Ahima RS, Kaestner KH, et al. Adiponectin suppresses gluconeogenic gene expression in mouse hepatocytes independent of LKB1-AMPK signaling. J Clin Invest 2011;121:2518-28.

16. Seoane M, Iglesias $P$, Gonzalez $T$, Dominguez F, Fraga M, Aliste $C$ et al. Retinoblastoma loss modulates DNA damage response favoring tumor progression. PLoS ONE 2008;3:e3632.

17. Soengas MS, Alarcon RM, Yoshida H, Giaccia AJ, Hakem R, Mak TW, et al. Apaf-1 and caspase-9 in p53-dependent apoptosis and tumo inhibition. Science 1999;284:156-159. 
Ríos et al.

18. Gillies RJ, Didier N, Denton M. Determination of cell number in monolayer cultures. Anal Biochem 1986;159:109-13.

19. Dasgupta B, Milbrandt J. AMP-activated protein kinase phosphorylates retinoblastoma protein to control mammalian brain development. Dev Cell 2009;16:256-70.

20. Randriamboavonjy V, Isaak J, Frömel T, Viollet B, Fisslthaler B Preissner KT, et al. AMPK $\alpha 2$ subunit is involved in platelet signaling, clot retraction, and thrombus stability. Blood 2010;116: 2134-40.

21. Yuk JM, Shin DM, Lee HM, Kim JJ, Kim SW, Jin HS, et al. The orphan nuclear receptor SHP acts as a negative regulator in inflammatory signaling triggered by Toll-like receptors. Nat Immunol 2011;12: 742-51.

22. Zhou G, Myers R, Li Y, Chen Y, Shen X, Fenyk-Melody J, et al. Role of AMP-activated protein kinase in mechanism of metformin action. $J$ Clin Invest 2001;108:1167-74

23. Fuxe J, Akusjärvi G, Goike HM, Roos G, Collins VP, Pettersson RF. Adenovirus-mediated overexpression of p15INK4B inhibits human glioma cell growth, induces replicative senescence, and inhibits telomerase activity similarly to p16INK4A. Cell Growth Differ 2000;11: 373-84.

24. Michaud K, Solomon DA, Oermann E, Kim JS, Zhong WZ, Prados MD, et al. Pharmacologic inhibition of cyclin-dependent kinases 4 and 6 arrests the growth of glioblastoma multiforme intracranial xenografts. Cancer Res 2010;70:3228-38.

25. Li Y, Guessous F, Kwon S, Kumar M, Ibidapo O, Fuller L, et al. PTEN has tumor-promoting properties in the setting of gain-of-function p53 mutations. Cancer Res 2008;68:1723-31.

26. Laderoute KR, Calaoagan JM, Madrid PB, Klon AE, Ehrlich PJ. SU11248 (sunitinib) directly inhibits the activity of mammalian $5^{\prime}$ AMP-activated protein kinase (AMPK). Cancer Biol Ther 2010;10: 68-76.

27. Laderoute KR, Amin K, Calaoagan JM, Knapp M, Le T, Orduna J, et al. $5^{\prime}$-AMP-activated protein kinase (AMPK) is induced by low-oxygen and glucose deprivation conditions found in solid-tumor microenvironments. Mol Cell Biol 2006;26:5336-47.
28. Kola B, Boscaro M, Rutter GA, Grossman AB, Korbonits M. Expanding role of AMPK in endocrinology. Trends Endocrinol Metab 2006;17: 205-15.

29. Mistry T, Digby JE, Desai KM, Randeva HS. Obesity and prostate cancer: a role for adipokines. Eur Urol 2007;52:46-53.

30. Salt I, Celler JW, Hawley SA, Prescott A, Woods A, Carling D, et al AMP-activated protein kinase: greater AMP dependence, and preferential nuclear localization, of complexes containing the alpha2 isoform. Biochem J 1998;334:177-87.

31. Suzuki A, Okamoto S, Lee S, Saito K, Shiuchi T, Minokoshi Y. Leptin stimulates fatty acid oxidation and peroxisome proliferator-activated receptor alpha gene expression in mouse $\mathrm{C} 2 \mathrm{C} 12$ myoblasts by changing the subcellular localization of the alpha2 form of AMP-activated protein kinase. Mol Cell Biol 2007;27:4317-27.

32. Kodiha M, Rassi JG, Brown CM, Stochaj U. Localization of AMP kinase is regulated by stress, cell density, and signaling through the MEK->ERK1/2 pathway. Am J Physiol Cell Physiol 2007;293: C1427-36.

33. McGee SL, Howlett KF, Starkie RL, Cameron-Smith D, Kemp BE Hargreaves M. Exercise increases nuclear AMPK alpha2 in human skeletal muscle. Diabetes 2003;52:926-8.

34. Culmsee C, Monnig J, Kemp BE, Mattson MP. AMP-activated protein kinase is highly expressed in neurons in the developing rat brain and promotes neuronal survival following glucose deprivation. J Mol Neurosci 2001;17:45-58.

35. Hashimoto K, Kato K, Imamura K, Kishimoto A, Yoshikawa H, Taketan $\mathrm{Y}$, et al. 5-Amino-4-imidazolecarboxamide riboside confers strong tolerance to glucose starvation in a $5^{\prime}$-AMP-activated protein kinase-dependent fashion. Biochem Biophys Res Commun 2002; 290:263-7.

36. Inoki K, Zhu T, Guan KL. TSC2 mediates cellular energy response to control cell growth and survival. Cell 2003;115:577-90.

37. Kato K, Ogura T, Kishimoto A, Minegishi Y, Nakajima N, Miyazaki M, et al. Critical roles of AMP-activated protein kinase in constitutive tolerance of cancer cells to nutrient deprivation and tumor formation. Oncogene 2002;21:6082-90. 


\section{Cancer Research}

AGR American Association

The Journal of Cancer Research (1916-1930) | The American Journal of Cancer (1931-1940)

\section{AMPK Activation by Oncogenesis Is Required to Maintain Cancer Cell Proliferation in Astrocytic Tumors}

Marcos Ríos, Marc Foretz, Benoit Viollet, et al.

Cancer Res 2013;73:2628-2638. Published OnlineFirst January 31, 2013.

Updated version Access the most recent version of this article at: doi:10.1158/0008-5472.CAN-12-0861

Supplementary Access the most recent supplemental material at:

Material http://cancerres.aacrjournals.org/content/suppl/2013/01/31/0008-5472.CAN-12-0861.DC1

Cited articles This article cites 37 articles, 13 of which you can access for free at:

http://cancerres.aacrjournals.org/content/73/8/2628.full\#ref-list-1

Citing articles This article has been cited by 20 HighWire-hosted articles. Access the articles at:

http://cancerres.aacrjournals.org/content/73/8/2628.full\#related-urls

E-mail alerts Sign up to receive free email-alerts related to this article or journal.

Reprints and To order reprints of this article or to subscribe to the journal, contact the AACR Publications Department a Subscriptions pubs@aacr.org.

Permissions To request permission to re-use all or part of this article, use this link http://cancerres.aacrjournals.org/content/73/8/2628.

Click on "Request Permissions" which will take you to the Copyright Clearance Center's (CCC) Rightslink site. 